\title{
FIÇÃO OITOCENTISTA EM TRADUÇÃO
}

Irene Hirsch

Pesquisadora da FAPESP

$\mathrm{O}$

bras literárias, orais ou escritas, antigas ou modernas, são recriações ou reescrituras de outras obras e a tradução é uma das formas mais óbvias de se reescrever em uma dada cultura. Teóricos da tradução, em especial André Lefevere, apontaram para a importância das refrações como forma de sobrevivência de um texto, sendo em grande parte responsáveis pela definição, manutenção e alteração do cânone.

Os modos de se processar um texto para diferentes públicos ou de o adaptar a uma determinada ideologia ou poética são inúmeros: além de traduções, as refrações podem se apresentar em forma de crítica, história literária, adaptação para o cinema, teatro, histórias em quadrinhos, antologias, adaptação para crianças etc.

Parto da premissa de que o número significativo de traduções e adaptações que compõem o mercado livreiro no Brasil é em grande parte responsável pela sua notável expansão nas últimas décadas, e o objeto do meu interesse é a integração dessas obras no espaço literário. Para tentar compreender como isso se dá examinarei as adaptações feitas para o público infanto-juvenil de autores norte-americanos do século XIX.

Tais ficcionistas foram adaptados várias vezes para atender às diferentes exigências de um mercado consumidor em expansão. Esse mercado foi setorizado, e os leitores contemplados com coleções dirigidas a públicos específicos como o feminino ou o infanto-juvenil. Os textos foram tratados como produtos industriais no âmbito da cultura, para atender a uma demanda de mercado. De acordo com a categorização de "tradução de fábrica", de John Milton, as edições voltadas 
ao público feminino e ao infantil pertencem ao grupo de "condensação explícita", ou seja, adaptações que foram condensadas para públicos específicos, como estratégia de marketing (MштоN, 2002, p.94). No caso das traduções, as "condensações explícitas" são as que trazem indicações claras de que o texto original foi alterado. Essas alterações tendem a ser simplificações do léxico, da sintaxe e redução da estrutura da obra. Dessa forma, o número de capítulos e de páginas de um texto acomoda-se ao padrão estabelecido pelo organizador da série. No processo de "infantilização" dos clássicos, observa-se também uma higienização, ou seja, retiram-se os episódios de conduta inconveniente, de rudeza ou de sexualidade explícita. Em suma, os textos são reescritos, editados, cortados ou reinventados para atender a leitores de épocas, de idades e de padrões morais diferentes. A literatura infantil, por exemplo, passa a ter como o objetivo atender o que se consideram ser as necessidades próprias da criança leitora, o que se concretiza na imposição de um código moral estritamente convencional.

Segundo Milton, a padronização dessas obras foi operada de modos diferentes, tomando-se como base o tema da obra, a linguagem da narrativa, o estilo do autor, o tamanho ou até mesmo o peso do livro:

a) tema: a obra é moldada de forma a adaptar-se ao gosto dos leitores; b) linguagem: linguagens de baixo padrão e dialetos são cortados; c) estilo: a obra não deve desviar-se de um estrito estilo narrativo; d) tamanho: o uso da mancha do papel diminuirá os custos de produção; e) peso: se o livro for distribuído pelo correio, o peso será um fator determinante no preço (MiLton, 2002, p.96).

Cumpre salientar também o papel das ilustrações nesse tipo de publicações. Além de simplificarem a compreensão, freqüentemente idealizadas que reforçam os padrões de boa conduta expressos no texto, por meio da representação de cenas idealizadas.

A segmentação do público, setorizado por idade, sexo ou profissão, gera a proliferação de publicações seriadas, que padronizam o aspecto gráfico, o tamanho e a linguagem das obras literárias, procurando estimular o consumo sucessivo de vários títulos. Desse modo, a organização em coleções ou séries é um fator importante de descaracterização dos textos, porque, além de promover uma padronização, promove também uma descontextualização: as obras literárias são agrupadas por critérios outros que as condições históricas que geraram os originais, para atender ao padrão ideológico dos intermediários do livro (editores, tradutores, escritores). 


\section{A criança leitora}

De acordo com Lyons, a "era de ouro" do livro no mundo ocidental, Europa, se deu quando a taxa de alfabetização atingiu $90 \%$ da população, sem discriminar homens ou mulheres (CAVALLO, 1999, p.165). No Brasil, assim como em outros lugares, a expansão da educação primária estimulou o crescimento de um setor importante do público leitor, qual sejam, as crianças. Surgiram revistas infantis e outros escritos para jovens, voltados para as preocupações pedagógicas. Gerou-se uma demanda por textos escolares e para-didáticos, que passaram a ocupar uma fatia maior do mercado de livros e colaboram para o crescimento de editoras como a Melhoramentos, a Ática, a Scipione, por exemplo, que dirigem seus produtos quase exclusivamente a esse setor.

A massificação do ensino fundamental no Brasil, no entanto, tem uma história recente. No Império, a população agrária não atribuía muita importância à leitura e à escrita. Embora a educação primária já figurasse como um dever do Estado na Constituição de 1824, a falta de instrução era a realidade para a maior parte do país. Os gastos nessa área no período imperial foram modestos e as instituições educativas eram poucas e elitistas. No Rio de Janeiro, por exemplo, havia apenas o Colégio Pedro II, o Imperial Observatório, o Museu Nacional, o Arquivo Público, a Biblioteca Nacional, o Laboratório do Estado, o Jardim Botânico e a Academia Imperial de Belas-Artes (ScHwarcz, 1998, p.155).

A situação na República, no entanto, inverteu-se. Pela Constituição brasileira de 1891, o direito de voto só cabia aos maiores de 21 anos que soubessem ler e escrever. A população, livre da escravidão, passou a valorizar a alfabetização. A educação popular foi um projeto da campanha dos liberais que pregavam a República, mas a educação livre, universal e gratuita não encontrou seu correspondente na prática. Por volta de 1890, 80\% da população brasileira era analfabeta e esse quadro não teve alteração significativa até 1920 (MARTins, 2001, p.200).

Apenas na década de 1960, quando foi aprovada a Lei de Diretrizes e Bases da Educação Nacional (Lei $n^{\circ} 4.024$, de 20/12/61), o ensino foi democratizado: a educação passou a ser "um direito de todos... e uma obrigação do Governo", e o período de escolaridade obrigatória foi estendido para oito anos. Nos currículos e programas elaborados segundo essas diretrizes, 
enfatizou-se a leitura como atividade importante no processo de aprendizagem, o que significou uma demanda crescente por livros literários (CoELHO, 1985, p.211).

Dados publicados pelo IBGE relativos ao Censo de 2000 mostram que o quadro de alfabetização se modificou ao longo do século: em 1991 a taxa de alfabetizados de 10 anos ou mais foi de 80,3\%, e em 2000 foi de $87,2 \%$. Ou seja, a expansão do mercado de livros foi impulsionada pelo crescimento significativo do público leitor, além do crescimento demográfico que houve - o total de habitantes em 2000 foi de 169.799.170.

A expansão e a planificação do setor educacional e o crescimento demográfico não foram, no entanto, as únicas condições necessárias para o crescimento do mercado editorial para o livro no Brasil. Há que se considerar igualmente a organização da indústria, que começou a produzir cultura numa escala de massa, no final dos anos de 1960. O golpe de 64 representou uma aliança dos interesses governamentais e de empresários da cultura em criar um mercado consumidor nacional, que incentivou o investimento tecnológico e a organização de setores culturais. Diversos setores da cultura expandiramse ao mesmo tempo em que o Estado criou a Embratel (1965), o Conselho Federal de Cultura (1966), o Ministério de Comunicações (1967), a Embrafilme (1969), a Funarte (1975) etc. (MonTERo, 1991, p.162).

O livro didático, filão mais rentável da indústria do livro, também se beneficiou da política do governo. Criou-se, em 1966, a Comissão Nacional do Livro Técnico e Didático (COLTED), financiada pelo MEC, USAID e SNEL, para favorecer o comércio livreiro e beneficiar o aspecto industrial da produção. Além das inovações tecnológicas, os editores começaram a utilizar estratégias de marketing, como a publicidade, e diversificação dos meios de distribuição - das bancas de revistas a supermercados, e até farmácias (MonTERo, 1991, p.163).

\section{As coleções de textos traduzidos na trajetória do livro infantil brasileiro}

As seções de literatura infantil, ao lado das pedagógicas, surgem nos periódicos na virada do século XIX: A Escola Pública (em 1896), O Cabrião 
(em 1897), Revista do Ensi o (em 1902), Álbum das Meninas (em 1898). Essas seções infantis eram constituídas de histórias traduzidas de autores estrangeiros, com contos de fadas, além de reproduzirem jogos de adivinhações, passatempos e curiosidades, muitas vezes ilustradas com gravuras, figurinhas etc., como apelo mercadológico (MARTins, 2001, p.406). As seções dirigidas às crianças tornaram-se revistas e livros no decorrer do século XX, com histórias ilustradas de autores brasileiros e estrangeiros.

É principalmente a partir da década de 1960 que as editoras começam a investir mais fortemente em empreendimentos comerciais visando ao público mais jovem. Surgem assim as coleções infanto-juvenis; algumas subordinadas ao tema "clássicos da literatura universal", publicaram adaptações ou condensações de obras de autores norte-americanos do século XIX, que serão examinadas a seguir. As editoras responsáveis por essas coleções foram, e parte delas ainda são, a Companhia Editora Nacional, Vecchi, Melhoramentos, Paulinas, Ediouro, Abril, Scipione e Ática. Além dessas adaptações, ainda se desenvolveu o setor das histórias em quadrinhos de "clássicos da literatura", publicadas pelas editoras Brasil-América (Ebal), Bruguera e Abril, dirigidas ao público jovem.

Todas essas coleções, publicadas em períodos diferentes, apresentaram formatos editoriais variados, mas a maioria delas publicou ilustrações junto com o texto condensado (exceção feita às coleções Audazes e Primavera).

\section{TERRAMAREAR}

Vários dos escritores norte-americanos do século XIX foram traduzidos, ou, para ser mais precisa, adaptados pela primeira vez pela Companhia Editora Nacional, e publicados nas diferentes coleções da editora. A coleção PARATodos era constituída de literatura estrangeira em geral, "apresentando os melhores romances nos gêneros de aventura, policial e histórico, é uma coleção popular, isto é, para todos”. A TERRAMAREAR era dirigida a rapazes, a SÉrie Negra era composta de livros policiais, e a Biblioteca das Moças, constituída de histórias sentimentais, como o nome o evidencia, era direcionada ao público jovem feminino. Essas coleções ajudaram a consolidar a editora, que surgira três meses após a falência da Monteiro Lobato e 
Cia, em 1925. A nova editora de Monteiro Lobato cumpriu um importante papel no mercado editorial brasileiro. Nesse empreendimento, Lobato associou-se a Octalles Marcondes Ferreira e começaram publicando vinte títulos, com sete reedições, apenas no primeiro ano (PAIXÃo, 1998, p.71). O primeiro livro a ser publicado foi Hans Staden. Segundo Lobato, tratava-se de uma coincidência que marcava um duplo começo:

Mando-te um Staden, a edição primogênita da nova companhia e, por coincidência, o primeiro livro que se publicou sobre o Brasil. É obra realmente interessante e merecedora do sucesso que têm tido. A edição inicial de 3 mil está no fim. Vamos tirar outra e maior (LoBATo, 1944, p. 463).

Além de ser um inovador da indústria brasileira do livro, à frente da editora com o seu nome e posteriormente da Companhia Editora Nacional, Lobato lançou um grande número de títulos traduzidos. A tradução foi para Lobato, após seu regresso dos Estados Unidos, em 1931, uma atividade profissional paralela à da criação de obras de literatura infantil, e que lhe garantia o sustento (Koshiyama, 1982, p.157). Traduziu 87 obras, das quais apenas cinco não foram publicadas pela Companhia Editora Nacional. Em carta a Godofredo Rangel, escreveu sobre o seu entusiasmo com a tradução:

Gosto imenso de traduzir certos autores. É uma viagem por um estilo. E traduzir Kipling, então? Que esporte! Que alpinismo! Que delícia remodelar uma obra de arte em outra língua! Estou agora a concluir um Jack London, que alguém daqui traduziu massacradamente. Adoro London com suas neves do Alaska, com o seu Klondike, com os seus maravilhosos cães de trenó (Loвato, 1944, p.493).

Monteiro Lobato pertencia ao grupo de intelectuais da época que acreditava que os Estados Unidos significavam progresso e que o Brasil poderia se modernizar com o estreitamento de laços entre os dois países.

A coleção Terramarear foi iniciada em 1931, sendo constituída de novelas de aventura destinadas aos jovens, como, por exemplo, o Tarzã de Edgar Rice Burroughs. Dentre os norte-americanos do século XIX, estão presentes nessa coleção James Fenimore Cooper e Jack London, com as obras $O$ corsário vermelho, $O$ último dos moicanos, $A$ aventureira, Caninos brancos 
e A filha da neve, traduzidos respectivamente por Godofredo Rangel, Agripino Griecco, Americo Neto e os dois últimos por Monteiro Lobato .

Diversas reedições das traduções da Companhia Editora Nacional foram publicadas em séries de aventuras, dirigidas a jovens por diferentes editoras, como a Brasiliense e a Abril. Recentemente o IBEP relançou as coleções com o mesmo nome, mas capas e formato diferentes.

\section{Os AudAzes}

A editora Vecchi, do italiano Artur Vecchi, instalou-se no Rio de Janeiro em 1913. Embora viesse a se especializar na edição de revistas e de livros infantis, proclama-se pioneira na edição brasileira de livros de Maurois, Ibsen, Gide, Schopenhauer e Nietzsche (Halleweld, 1985, p.203). Segundo Marlise Meyer, a Vecchi explorou a comercialização do romance popular com o potencial de mercado aberto pelo alargamento das classes populares no Brasil do começo do século:

A Vecchi o comercializa num circuito completo. Faz a impressão e a distribuição para todo o país em forma de fascículos de dezesseis páginas semanais; entrega de casa em casa, precedidos por um folheto demonstrativo ricamente colorido, com promessas de brindes e chamadas excitantes, sendo os dez primeiros números gratuitos (MEYER, 1996, p.346).

Os livros da coleção Os AudAzes tiveram formato pequeno, (de 14 x $19 \mathrm{~cm}$, com 180 a 200 páginas), não eram ilustrados e sua impressão era feita em papel barato, que precisava ser cortado com espátula para que o livro possa ser lido. Para assegurar que todos os volumes tivessem o mesmo tamanho, os diagramadores não padronizaram o número da fonte: originais longos, como As aventuras de Huck, foram exprimidos nos $14 \times 19 \mathrm{~cm}$, com letras pequeníssimas, ao passo que $A$ hiena dos mares, por ser mais curto, foi impresso em fonte mais legível. Nessa coleção foram publicadas obras de autores como Mark Twain, James Fenimore Cooper, Richard Dana e Edgar Allan Poe.

\section{OBRAS CÉLEBRES}

A Melhoramentos foi constituída em 1890 e iniciou a produção editorial em 1915, com a sua fusão com a Weiszflog Irmãos. Além de fabricar papel, os 
empreendimentos da Melhoramentos passaram a incluir publicações variadas como livros de culinária, dicionários, atlas, livros de bolso, entre outros. Hallewell observa que, apesar de o catálogo da Melhoramentos não abrigar muitos títulos de ficção, a editora foi responsável por um dos maiores fenômenos literários brasileiros, que foi José Mauro de Vasconcelos (Rosinha, minha canoa, 1962, e Meu pé de laranja lima, 1968). No entanto, a viga mestra da atividade editorial foram sempre a literatura infanto-juvenil (publicada sob outras rubricas além das coleções aqui citadas) e os livros didáticos, responsáveis por dois terços da produção total, em títulos.

Do mesmo modo que outras editoras, publicou diversas vezes uma mesma adaptação de autores como Herman Melville, Fenimore Cooper, Jack London, Frances Burnett e Harriet Beecher Stowe em coleções diferentes: Obras Célebres, No Mundo da Aventura, A Aventura de Ler, Obras Primas Universais, e Cluássicos Ilustrados.

A Melhoramentos continua hoje atuando nos setores editorial, gráfico e de fabricação de papel, sendo que a editora ocupa o $12^{\circ}$ lugar em volume de títulos, de acordo com estatísticas do ISBN referentes a 1999.

\section{PRIMAVERA}

As congregações Paulinas, de padres e de religiosas, que têm suas raízes em Alba, no norte da Itália, iniciaram seu trabalho de difusão da "boa leitura" junto às famílias de imigração italiana do bairro paulistano do Brás, no final da década de 1920. A Paulinas Editora foi fundada em São Paulo, no ano de 1931, por iniciativa das Irmãs Dolores Baldi e Stefanina Cillario e do Padre Tiago Alberione, fundador da Congregação das Filhas de São Paulo (Irmãs Paulinas). A editora surgiu da associação das duas congregações paulinas, masculina e feminina, atendendo ao objetivo comum de utilizar os meios de comunicação de massa para evangelizar. Nessa associação, as duas congregações mantiveram-se juridicamente separadas e dividiram o trabalho editorial entre si: a linha bíblica e teológica seria editada pelos paulinos; a linha catequética, infantil e biografias, pelas paulinas.

No início, as irmãs distribuíam o semanário La Squilla, o folheto litúrgico "O Domingo" e vendiam livros sobre a vida de santos e catecismos. Em 1934, adquiriram uma máquina tipográfica e editaram a versão brasilei- 
ra da revista italiana Familia Cristã. Na década de 1950, com a produção da coleção DoutRINA CRISTÃ, as Irmãs Paulinas alcançaram a cifra de 5,3 milhões de exemplares impressos (MonTERo, 1991, p.165).

Atualmente, a editora Paulinas é uma empresa que conta com um conselho editorial, analistas, tradutores, desenhistas, diagramadores, fotógrafos e gráficos, entre outros profissionais, que conseguem publicar mais de um livro por dia, como está declarado em seu site. Sempre voltada para assuntos religiosos, diversificou sua produção, sendo responsável por vários tipos de bens culturais como livros, fitas, CDRoms, DVDs, etc. Na tabela das estatísticas do ISBN, a editora está colocada entre as vinte mais importantes do período de 1978 a 1999, com 1410 títulos cadastrados. Ou seja, o surgimento de uma indústria de bens culturais de massa no Brasil propiciou uma expansão do consumo de bens religiosos e, como conseqüência, um aumento da capacidade de produção desses bens.

Na década de 1960, a coleção Primavera publicou três autores norteamericanos do século XIX: Louisa May Alcott, Mark Twain e Frances Burnett. Anteriormente, em 1958, havia publicado A cabana do pai Tomás, de Harriet Beecher Stowe, na coleçãn Os GRANDES ROMANCES DO CRISTIANISMO. Foi responsável pela tradução de grande parte da obra de Louisa May Alcott (Mulherzinhas, Mulherzinhas crescem, Oito primos, Rosa em flor, Rapaziada de Jó) e pelos livros Pequeno lorde, Príncipe e mendigo de Burnett e Twain.

\section{ELEFANTE}

A Ediouro é a editora que publicou o maior número de adaptações infanto-juvenis de ficção norte-americana do século XIX, somando 24 títulos no total. As diferentes coleções da editora - Elefante, Baleia Bacana, Extra, Alexandre Dumas, Mark Twain, Júlio Verne, Até 12 anos, Calouro Maior compartilharam às vezes uma mesma adaptação de uma dada obra. Em alguns casos, as adaptações foram feitas por importantes nomes da literatura brasileira como, por exemplo, Clarice Lispector, que adaptou os norteamericanos Edgar Allan Poe e Jack London (11 de Allan Poe e Chamado selvagem ), e Carlos Heitor Cony, que fez as adaptações de Herman Melville e de seis obras de Mark Twain (Moby Dick, Diário de Adão e Eva, Um ianque na corte do rei Arthur, $O$ príncipe e o pobre, $O$ roubo do elefante branco, Tom Sawyer detetive, Viagens de Tom Sawyer e Aventuras de Huck). 
Outros autores norte-americanos do século XIX adaptados para essas coleções foram Louisa May Alcott (Um colégio diferente, As filhas do Dr. March), James Fenimore Cooper ( $O$ último dos moicanos), Harriet Beecher Stowe ( $A$ cabana do pai Tomás), Frances Burnett (A pequena princesa, Davi, o órfão), Jack London (Lobo do mar), Eleonor Porter (Poliana, Poliana moça) e Henry James (Os inocentes).

A Tecnoprint Gráfica foi uma firma constituída por Jorge Gertrum Carneiro, um médico gaúcho, seu irmão Antônio Carneiro, engenheiro, e Frederico Mannheimer, um refugiado da Alemanha nazista. O primeiro livro foi publicado em 1939, Fala e escreve corretamente tua língua, de Luís Vitória. Em seguida importaram livros, tentaram editar livros de medicina e engenharia, revistas, sem conseguir sucesso financeiro. No final da década de 1950, fizeram publicações eróticas em suas Edições SEGREdo (Meu destino é pecar, de Suzanna Flag, pseudônimo de Nelson Rodrigues, é uma delas). De Publicações Pan Americanas, mudaram sua marca para Edições de Ouro, voltada para livros de bolso e acrescentaram a coleção COQUETEL DE PALAVRAS Cruzadas (Hallewell, 1985, p.563). Seu catálogo inclui livros práticos, manuais de auto-educação, ficção, história, filosofia. Declaram em seu site: “A Ediouro possui cerca de 3.500 títulos... livros de inspiração, auto-ajuda, gastro omia, artes plásticas, filosofia, sexo, medicina, história, religião, humor, psicologia, economia e negócios...”. Na ficha de catalogação da Biblioteca Nacional o item "linha editorial" tem 56 entradas, com temas ainda mais variados como, por exemplo, ufologia, numerologia, contabilidade, datilografia, entre outros.

Esse perfil mercadológico, diferente daquele ideológico presente na Paulinas, possibilitam uma maior flexibilidade por parte da linha editorial para publicar um número maior de adaptações contemplando temas diversos.

\section{Clássicos da Literatura Juvenil}

A editora Abril, criada em São Paulo por Victor Civita em 1950, foi inaugurada com a publicação da revista Pato Donald, de Walt Disney. Entre 1950 e 1959 editou sete títulos; na década seguinte, o número de títulos cresceu para 27, e no período entre 1970 e 1979 chegou a 121 títulos. A 
produção se diversificou com a publicação de fotonovelas como Capricho (1952), de revistas femininas como Manequim (1959), e de revistas para o público masculino como Quatro Rodas (1960) entre outras. Nos anos 70 multiplicaram-se os títulos infantis como Cebolinha, Luluzinha, Piu-Piu, Enciclopédia Disney, etc. O crescimento da empresa foi vertiginoso: a tiragem de um título, Pato Donald, de 83 mil exemplares, em 1950, deu lugar a uma tiragem de setenta títulos infantis, com 90 milhões de exemplares, em 1986 (ORTIZ, 2001, p.123).

A diversificação de bens culturais fez com que a empresa Abril se tornasse um conglomerado de negócios que, além das revistas, atua hoje também nas áreas de multimídia, educação (Fundação Victor Civita), internet (@Jato), entretenimento (MTV), cabo (TVA) e database marketinw. Em 2000, com cerca de 8.000 funcionários, teve uma receita líquida de $\mathrm{R} \$ 1,839$ bilhões. O principal produto ainda são as revistas, que representam $64 \%$ dos negócios, com 233 títulos por ano, 224 milhões de exemplares vendidos em 2000, e 4,6 milhões de assinaturas, segundo informações do site da editora. As editoras Abril, Círculo do Livro, Nova Cultural e Best Seller pertencem todas ao mesmo grupo; em 1999 foram acrescentadas as editoras Ática e Scipione.

A primeira incursão da Abril no mercado de livros foi com $A$ Biblia mais bela do mundo, em 1965, vendida em fascículos quinzenais em bancas de jornal. Outras séries se sucederam como Pequeno dicionário da língua portuguesa ilustrado, Livro da vida, Enciclopédia Abril, etc. Na área de literatura traduzida, foram publicadas as séries Os imortais e Clássicos da literatura juvenil. Esta última foi uma coleção luxuosa de clássicos traduzidos, dirigida aos jovens, iniciada na década de 1970. Em sua grande parte, a coleção foi composta de traduções que já haviam sido publicadas pela Companhia Editora Nacional, Brasiliense, Ediouro e Paulinas, entre outras, mas que receberam um novo tratamento editorial: livros de capa dura com novas ilustrações feitas por artistas gráficos. Os tradutores eram renomados autores como Monteiro Lobato, Herberto Salles e Miécio Tati. A coleção completa é constituída de mais de trinta títulos; entre eles, traduções de Louisa May Alcott, Francis Burnett, James Fenimore Cooper, Herman Melville, Jack London e Mark Twain, com os títu| os Mulherzinhas, O pequeno lorde, Rapaziada de Jó, $O$ último dos moicanos, Moby Dick, a fera do mar, Chamado selvagem, $O$ príncipe e o mendigo, Aventuras de Tom Sawyer e Aventuras de Huck. 
Vale reforçar, como os títulos permanecem os mesmos, que havia um nicho de interesse por parte do público e um receio de lançar novos títulos ou novas traduções por parte da Abril. A embalagem mudara, tornando-se mais sofisticada, mas os textos permaneciam os mesmos.

\section{REENCONTRO}

A editora Scipione foi fundada pelo professor Scipione Di Piero Netto. Em 1983, quando foi comprada pela Ática, a editora Scipione tinha um catálogo de cinco títulos e vendia 100 mil exemplares por ano. Em fins de 1999 foi comprada, juntamente com a Ática, pelo grupo francês Havas em associação com a Abril. Há filiais em São Paulo, Rio de Janeiro, Brasília, Salvador e Recife.

A série REENCONTRO foi lançada em 1986 e é constituída de adaptações de clássicos da literatura universal "com linguagem simples e atual de grandes escritores de todos os tempos”, e classifica-se como uma coleção de livros paradidáticos. É composta de 37 títulos subdivididos em quatro temas (aventura, mistério, humor e romance), indicados para alunos da $5^{\mathbf{a}}$ série até o $2^{\circ}$ grau. Os livros têm um formato pequeno, 21 x $14 \mathrm{~cm}$, e não ultrapassam as 140 páginas; as ilustrações são bem cuidadas, com traços modernos em preto e branco. Todos os livros da série trazem informações sobre o escritor que fez a adaptação e têm uma ficha de leitura anexada, com perguntas e atividades.

Foram lançados os norte-americanos Os inocentes (James), $O$ mexicano: livro do professor (London), Moby Dick, a baleia branca (Melville), Assassinatos da rua Morgue (Poe) e O príncipe e o mendigo (Twain).

A coleção REENCONTRO vem mostrar que as adaptações vão ganhando um certo prestígio no decorrer do tempo, já que o adaptador ganha espaço na edição, o que tem o óbvio intuito de valorizar tal atividade aos olhos do público.

EU LEIO

A editora Ática foi fundada em 1965, como conseqüência da expansão da Sesil (Sociedade Editora do Santa Inês). O curso de madureza Santa Inês foi fundado em 1956 por Anderson Fernandes Dias, Vasco Fernandes Dias e Antonio Narvaes Filho. Seu início foi, portanto, marcado pela publicação de material 
didático e para-didático, como as coleções Estudo DIRIGIDO DE PORTUGUÊs, PARA GOSTAR DE LER e BOM LIVRO, entre outras. Os autores estrangeiros foram reunidos na série EU LEIO, iniciada em 1995. Essa série da Ática se propõe a publicar textos integrais.

\section{Os autores norte-americanos do século XIX}

Vários escritores norte-americanos do século XIX como Mark Twain, James Fenimore Cooper, Herman Melville, Harriet Beecher Stowe, Francis Burnett, Eleanor Porter, Louisa May Alcott, O. Henry e Jack London ficaram conhecidos como escritores para um público infantil devido ao grande número de adaptações publicadas foram. De todos o mais publicado nas coleções infanto-juvenis foi Mark Twain. Louisa May Alcott é outra autora publicada muitas vezes, só que ora em coleções para moças, ora em coleções para jovens.

Escritores como Nathaniel Hawthorne e Henry James também foram publicados em coleções infantis, porém não ficaram conhecidos como escritores do gênero. Henry James aparece em algumas coletâneas infanto-juvenis com o conto The Turn of the Screw, possivelmente porque os protagonistas são crianças. Nathaniel Hawthorne, no início de sua carreira, escreveu livros para crianças que são praticamente desconhecidos aqui. Orígenes Lessa fez adaptações de algumas dessas histórias, que foram publicadas pela Ediouro, e a Abril fez uma adaptação em quadrinhos de Scarlet Letter. Nenhum dos dois autores foi publicado pela Companhia Editora Nacional, ou traduzido por Monteiro Lobato, fato que explica em parte sua exclusão do panteão dos escritores para crianças.

É preciso fazer uma distinção entre os autores que escreveram para um público jovem e os autores que foram adaptados para esse mesmo público. Eleonor H. Porter ou Francis Burnett são exemplos de escritores de romances para crianças, enquanto Edgar Allan Poe não o é necessariamente. Mas todos os três, junto com Nathaniel Hawthorne e Herman Melville, fazem parte do rol dos mais importantes expoentes do romantismo norte-americano. Nessa literatura norte-americana do século XIX, o "sonho americano", representado pelas fábulas otimistas como Poliana ou $O$ pequeno lorde, sempre esteve acompanhado do "pesadelo americano", representado pela literatura niilista e cética de Moby-Dick, por exemplo. Ou seja, de certo modo, a 
indústria cultural padronizou as obras literárias desse período, e estilizou-as, colocando lado-a-lado escritores tão distintos quanto Henry James, Eleanor H. Porter e Herman Melville.

\section{Conclusão}

As coleções de literatura infanto-juvenil traduzida de escritores norteamericanos do século XIX, portanto, apesar de sua feição massificada, foram facilitadoras do contato do leitor com os clássicos. Paradoxalmente, a cultura de massas, ao mesmo tempo em que serviu de instrumento para a dominação ideológica norte-americana, democratizou a informação. Como disse antes, a leitura dos clássicos é comumente antecedida por leituras de comentários, críticas, resumos, condensações, e, inclusive por adaptações infanto-juvenis para o cinema ou para o teatro, assegurando dessa forma a sobrevivência do original.

A dimensão metonímica dessas reescrituras é um fator importante de mudança e de permanência cultural, na medida em que possibilita a adaptação de formas e de conteúdos às circunstâncias geradas pelas novas relações de consumo instituídas pelo mercado cultural.

Gostaria, portanto, de ressaltar que a integração dessas obras estrangeiras no espaço literário nacional além de implicar na expansão do setor livreiro no Brasil contribuiu para o engrandecimento do patrimônio cultural nacional: ao serem traduzidas para o português essas adaptações tornaram autores clássicos acessíveis ao público leitor brasileiro.

\section{BIBLIOGRAFIA}

Cavallo, Guglielmo \& Chartier, Roger. História da leitura no mundo ocidental 2. São Paulo: Ática, 1999

Coelho, Nelly Novaes. Panorama histórico da literatura infantil/juvenil. São Paulo: Quíron, 1985.

Hallewell, Laurence . O livro no Brasil. São Paulo: T.A. Queiroz e Edusp, 1985

Koshiyama, Alice. Monteiro Lobato intelectual, empresário, editor. São Paulo: T. A. Queiroz, 1982. 
Lobato, Monteiro. A barca de Gleyre. São Paulo: Companhia Editora Nacional, 1933.

Martins, Ana Luiza. Revistas em revista: imprensa e práticas culturais em tempos de República, São Paulo (1890-1922). São Paulo: EDUSP: FAPESP: Imprensa Oficial do Estado, 2001.

Meyer, Marlyse. Folhetim: uma história. São Paulo: Companhia das Letras, 1996.

Milton, John. O Clube do Livro e a tradução. Bauru: EDUSC, 2002.

Montero, Paula \& Delda Cava, Ralph...E o verbo se faz imagem. Petrópolis: Vozes, 1991.

OrTiZ, Renato. A moderna tradição brasileira. São Paulo: Brasiliense, 2001.

PAIXão, Fernando. Momentos do livro no Brasil. São Paulo: Ática, 1998

Schwarcz, Lilia Moritz. As barbas do imperador. São Paulo: Companhia das Letras, 1998

SodRÉ, Nelson Werneck. História da imprensa no Brasil. Rio de Janeiro: Mauad, 1998. 